\title{
The Effect of Single Point and Two Point Technique for Ultrasound Guided Supraclavicular Brachial Plexus Block in Patients Undergoing Elbow, Forearm and Wrist Surgeries- A Prospective Observational Study
}

\author{
Nikhil Maruthi Pallath ${ }^{1}$, Murali Shankar Bhat², Raghavendra Rajashekhar Huchchannavar ${ }^{3}$ \\ ${ }^{1}$ Department of Anaesthesiology and Critical Care, K. S. Hegde Medical Academy, Nitte \\ University, Mangalore, Karnataka, India. ${ }^{2}$ Department of Anaesthesiology and Critical \\ Care, K. S. Hegde Medical Academy, Nitte University, Mangalore, Karnataka, India. \\ ${ }^{3}$ Headquarters Dakshin Bharat Area, Army Medical Corps, India.
}

\section{ABSTRACT}

\section{BACKGROUND}

Use of ultrasound for brachial plexus block has improved the precision of drug deposition around the plexus and hence the quality of the block. But there has been debate whether single point technique or double point technique is superior. Our aim was to compare the two techniques for the onset, completeness and quality of the block.

\section{METHODS}

A prospective observational study was designed. 140 patients were equally divided into Group A and Group B containing 70 posted for elbow, forearm and wrist surgery. A drug solution of $30 \mathrm{ml}$ was prepared using Ropivacaine $0.75 \% 15 \mathrm{ml}+$ Lignocaine $2 \%$ with adrenaline $10 \mathrm{ml}+5 \mathrm{ml}$ of normal saline. Group A received $30 \mathrm{ml}$ of drug at the lower end of brachial plexus at 7 O'clock position. Group B received $15 \mathrm{ml}$ of drug at site mentioned above and $15 \mathrm{ml}$ was given at the upper part of brachial plexus at 11 O'clock position. Parameters noted were time taken for giving block, onset and completeness of sensory and motor block, encircle time, total duration of block. Unpaired student $t$ test used for comparing quantitative variables and Chi-square test for qualitative variables. $\mathrm{p}<0.05$ was considered statistically significant.

\section{RESULTS}

The time required for giving the block was more in Group B (198.57 $\pm 19.56 \mathrm{sec}$ ) compared to Group A (151.53 $\pm 14.37 \mathrm{sec})$ but the encircle time in Group B (16 \pm $3.32 \mathrm{~min})$ was lesser than Group A (19.01 $\pm 3.6 \mathrm{~min})$. The time of onset and completion of sensory and motor block for musculocutaneous, radial, ulnar and median nerve was faster in Group B compared to Group A. Duration of block in Group A was $367 \pm 50.49$ minutes, whereas in group B $388 \pm 49.98$ minutes.

\section{CONCLUSIONS}

In ultrasound guided brachial plexus block, even though both techniques have satisfactory results, double point technique is superior to single point technique in terms of onset, completeness and duration of the block but in terms of simplicity in technicality single point technique has the upper hand.

\section{KEY WORDS}

Ultrasound Guided, Supraclavicular Brachial Plexus Block, Single Point Technique, Double Point Technique

\author{
Corresponding Author: \\ Murali Shankar Bhat, \\ Assistant Professor, \\ Department of Anaesthesiology and \\ Critical Care, K. S. Hegde Medical Academy, \\ Deralakatte, Mangalore-575018, \\ Karnataka, India. \\ E-mail: muralishankarbhat@gmail.com
}

DOI: 10.14260/jemds/2020/169

Financial or Other Competing Interests: None.

How to Cite This Article:

Pallath NM, Bhat MS, Huchchannavar RR. The effect of single point and two point technique for ultrasound guided supraclavicular brachial plexus block in patients undergoing elbow, forearm and wrist surgeries- a prospective observational study. J. Evolution Med. Dent. Sci. 2020;9(10):776-779, DOI: 10.14260/jemds/2020/169

Submission 04-01-2020,

Peer Review 14-02-2020

Acceptance 20-02-2020,

Published 09-03-2020.

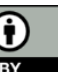




\section{BACKGROUND}

Brachial plexus block is widely used for anaesthetising the upper limb. The plexus can be blocked at different levels using different approaches such as interscalene, supraclavicular, infraclavicular and axillary approach. Supraclavicular approach is popular among the anaesthesiologists for giving brachial plexus block for elbow and forearm surgeries. In this approach the drug is deposited at the brachial plexus trunk where almost the entire sensory, motor and sympathetic innervation of the upper extremity is carried in just three nerve structures in a small area giving rise to a dense blockade. This approach carries complications such as inadvertent puncture of subclavian vasculatures, pneumothorax because of its proximity to subclavian vasculatures and the pleura ${ }^{1,2}$. Various techniques and instrument aids were introduced to reduce the complications. One among them and popular one is the ultrasound guided technique, which is practiced worldwide nowadays. The introduction of the ultrasound in anaesthesia has revolutionised the practice over the last few years. The nerves at supraclavicular level are superficial and can be easily located with high frequency linear probe $(8-18 \mathrm{mHz})$. The nerve plexus appears as hypoechoic shadows surrounded by hyperechoic rims, lateral to subclavian artery which are placed above the first rib, classically described as 'honeycomb' appearance. The subclavian artery is appreciated as a pulsating vessel above first rib. Usually the ultrasound probe is placed transversely and needle introduced by 'in plane' technique because it helps in visualising entire length of the needle along with the tip. This has improved the precision of drug deposition around nerve plexus, thus improving the quality of block and reducing the complications. $^{2}$

Anaesthesiologists practice different techniques for depositing the drug around the brachial plexus such as single point, double point, multiple point injection technique. ${ }^{3}$ Multiple point injection technique is most popular among these. However multiple punctures during the conduct of the block can increase the incidence of nerve injury as shown in many studies. ${ }^{4-6}$ This complication may be minimised by reducing the number of pricks attempted while giving the block. This can be an advantage with single point technique. A very few studies have been conducted comparing these techniques. Even though researchers have compared between single point and two point injection technique and shown good success rates with both the techniques, it is still debatable which of the two above mentioned techniques are superior.3,8,9,10 There is no enough data in Indian subpopulation on this topic.

We hypothesized that the single point injection technique is equally effective as two point injection technique for ultrasound guided supraclavicular brachial plexus block for the incidence and completeness and efficiency of the block in patients undergoing forearm surgeries.

\section{METHODS}

A prospective double blinded observational study was designed after obtaining Institutional ethical committee clearance. All ASA physical status I, II patients belonging to age group 18 to 65 years weighing more than $50 \mathrm{~kg}$ posted for elbow, forearm, wrist and hand surgery were included in the study. Patients with ASA physical status III, IV, skin infection at the site of injection and hypersensitivity to the drug were excluded from the study. Written informed consent was taken from every patient. The study duration was between June to December 2018.

140 patients were included in the study and they were divided randomly into Group A and Group B containing 70 patients in each group. Sample size arrived by using the formula-

$\mathrm{n}=\left(1+\frac{1}{\mathrm{k}}\right)\left(\sigma \frac{\mathrm{Z}_{1-\alpha / 2}+\mathrm{Z}_{1-\beta}}{\mu_{\mathrm{A}}-\mu_{\mathrm{B}}}\right)^{2}$

With $\alpha=5 \%$, Power $=80 \%, \mu_{\mathrm{A}}=22, \mu_{\mathrm{B}}=18, \sigma=8, \kappa=1$

Premedication was given as per institutional protocol. Patients were shifted to operation theatre and ECG, NIBP, pulse oximeter were attached and IV fluid was started. Patients were positioned supine. A drug solution of $30 \mathrm{ml}$ was prepared using Inj. Ropivacaine $0.75 \% 15 \mathrm{ml}$, Inj. Lignocaine $2 \%$ with adrenaline $10 \mathrm{ml}$ and $5 \mathrm{ml}$ of normal saline. Under aseptic precautions, using high frequency linear ultrasound probe (6-13 MHz, sonosite), subclavian artery and brachial plexus were visualized on the operative site. Brachial plexus block was performed using 'in plain technique' with $50 \mathrm{~mm}$ 'echogenic needle'. In group A, $30 \mathrm{ml}$ of the drug solution was given at the lower end of the brachial plexus above the first rib just lateral to the lower part of the subclavian artery $(7$ O'clock position) as shown in figure 1 . In group B, $15 \mathrm{ml}$ of the drug solution was given at the $7 \mathrm{O}^{\prime}$ clock position as mentioned above and $15 \mathrm{ml}$ was given at the upper part of the brachial plexus lateral to the subclavian artery (11 O'clock position) as shown in figure 2. After visualizing the brachial plexus, the time taken for giving block was noted. Patients were assessed for onset and completeness of block for sensory and motor block every minute after giving block by an independent observer who was blinded from the technique which was followed.

Pain sensation checked with 23 G hypodermic needle over the lateral aspect of the forearm (Musculocutaneous nerve), volar aspect of thumb (Median nerve), lateral aspect of the dorsum of the hand (Radial nerve) and volar aspect of the fifth finger (Ulnar nerve). The onset of sensory blockade was considered when there was a loss of sensation to pinprick. Completion of the sensory block was considered when there was a complete loss of sensation for touch.

The onset of motor blockade was considered when the patient showed weakness in performing elbow flexion (Musculocutaneous nerve), thumb abduction (Radial nerve), thumb opposition (Median nerve) and thumb adduction (Ulnar nerve). Completion of motor block considered when the patient could not do above mentioned actions completely on command.

Completeness of the block was considered when there was a blockade of both sensory and motor functions. Encircle time was calculated from the time after giving block until the drug completely surrounds the brachial plexus when visualized through ultrasound. 
The block was considered to be failure when even after 30 minutes after the deposition of the drug solution there was no signs of sensory or motor block or patient complained of pain during the surgery. If the patient complained of mild discomfort, analgesia was provided with Inj. Fentanyl 2 $\mu \mathrm{g} / \mathrm{kg}$. The duration of the block was calculated from the time the complete block achieved to the time when the patient complained of pain during the post-operative period. The patient was monitored for the pulse, blood pressure, oxygen saturation and ECG throughout the procedure. Any complications or side effects during the intraoperative and postoperative period were noted.

\section{Statistical Analysis}

Statistical analysis was done using SPSS software. Unpaired Student $t$ test used for comparing quantitative variables and the Chi-square test for qualitative variables. $\mathrm{p}<0.05$ was considered statistically significant.

\section{RESULTS}

Both groups were comparable in terms of demographic data such as age, sex and weight. (Table 1,2)

\begin{tabular}{|cccc|}
\hline & Group A & Group B & p value \\
Age (in years) & $39.91 \pm 10.48$ & $39.54 \pm 10.88$ & 0.84 \\
Weight (in kgs) & $68.66 \pm 8.3$ & $68.69 \pm 8.65$ & 0.98 \\
\hline & Table 1. Demographic Data \\
\hline
\end{tabular}

\begin{tabular}{|ccc|}
\hline & Group A & Group B \\
Male & $36(51.4 \%)$ & $37(52.8 \%)$ \\
Female & $34(48.6 \%)$ & $33(47.2 \%)$ \\
\hline Table 2. Showing Number of Males and Females
\end{tabular}

\begin{tabular}{|c|c|c|c|c|c|c|c|c|c|}
\hline & & \multicolumn{2}{|c|}{$\begin{array}{c}\text { Musculo- } \\
\text { cutaneous Nerve }\end{array}$} & \multicolumn{2}{|c|}{$\begin{array}{l}\text { Median } \\
\text { Nerve }\end{array}$} & \multicolumn{2}{|c|}{$\begin{array}{l}\text { Radial } \\
\text { Nerve }\end{array}$} & \multicolumn{2}{|c|}{$\begin{array}{l}\text { Ulnar } \\
\text { Nerve }\end{array}$} \\
\hline & & $\begin{array}{l}\text { के } \\
+1 \\
\text { त्ञ } \\
\sum\end{array}$ & 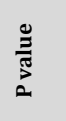 & $\begin{array}{l}\text { की } \\
+1 \\
\text { त्ञ } \\
\sum^{\infty}\end{array}$ & $\begin{array}{l}\frac{y}{\pi} \\
\frac{\pi}{2} \\
\text { ह }\end{array}$ & $\begin{array}{l}\text { के } \\
+1 \\
\text { त्ञ } \\
\sum_{\Sigma}^{\infty}\end{array}$ & $\begin{array}{l}\frac{g}{\pi} \\
\frac{\pi}{\pi} \\
\text { a }\end{array}$ & $\begin{array}{l}\text { के } \\
+1 \\
\text { ॠే } \\
\sum\end{array}$ & 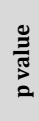 \\
\hline $\begin{array}{c}\text { Loss of pain } \\
\text { (onset of } \\
\text { sensory } \\
\text { block) }\end{array}$ & $\begin{array}{c}\text { Group } \\
\text { A } \\
\text { Group } \\
\text { B }\end{array}$ & $\begin{array}{c}9.79 \pm \\
1.6 \\
7.47 \pm \\
1.78\end{array}$ & $\begin{array}{l}\tilde{\sigma} \\
\dot{0} \\
\mathrm{v}\end{array}$ & $\begin{array}{c}11.37 \pm \\
1.8 \\
8.29 \pm \\
1.58\end{array}$ & $\underset{\dot{Q}}{\dot{v}}$ & $\begin{array}{c}12.6 \pm \\
2.32 \\
8.8 \pm \\
1.87\end{array}$ & $\begin{array}{l}\tilde{\sigma} \\
\dot{0} \\
\mathrm{v}\end{array}$ & $\begin{array}{l}12.9 \pm \\
2.25 \\
8.3 \pm \\
2.07\end{array}$ & $\begin{array}{l}\tilde{\sigma} \\
\dot{0} \\
\mathrm{v}\end{array}$ \\
\hline $\begin{array}{l}\text { Loss of touch } \\
\text { (Complete } \\
\text { sensory } \\
\text { block) }\end{array}$ & $\begin{array}{c}\text { Group } \\
\text { A } \\
\text { Group } \\
\text { B }\end{array}$ & $\begin{array}{c}13.67 \pm \\
1.8 \\
10.97 \pm \\
4.21\end{array}$ & $\stackrel{\overrightarrow{0}}{\dot{\rho}}$ & $\begin{array}{c}15.66 \pm \\
4.37 \\
12.24 \pm \\
2.10\end{array}$ & $\stackrel{\overrightarrow{0}}{\dot{i}}$ & $\begin{array}{c}17.04 \pm \\
4.29 \\
13.18 \pm \\
2.16\end{array}$ & $\stackrel{-}{0}$ & $\begin{array}{c}17.57 \pm \\
4.25 \\
12.69 \pm \\
2.61\end{array}$ & $\underset{\mathrm{o}}{\mathrm{o}}$ \\
\hline $\begin{array}{c}\text { Motor } \\
\text { weakness } \\
\text { (Onset of } \\
\text { motor block) }\end{array}$ & $\begin{array}{l}\text { Group } \\
\text { A } \\
\text { Group } \\
\text { B }\end{array}$ & $\begin{array}{c}13.37 \pm \\
3.49 \\
10.49 \pm \\
2.02\end{array}$ & $\begin{array}{l}\tilde{b} \\
\dot{0} \\
\mathrm{v}\end{array}$ & $\begin{array}{c}15.46 \pm \\
3.82 \\
12.06 \pm \\
2.32\end{array}$ & $\underset{\mathrm{i}}{\mathrm{i}}$ & $\begin{array}{c}16.47 \pm \\
3.94 \\
12.91 \pm \\
2.95\end{array}$ & $\underset{\mathrm{O}}{\dot{0}}$ & $\begin{array}{c}17.54 \pm \\
3.74 \\
13.0 \pm \\
3.74\end{array}$ & $\begin{array}{l}-1 \\
\dot{0} \\
\mathrm{v}\end{array}$ \\
\hline $\begin{array}{l}\text { Complete } \\
\text { motor block }\end{array}$ & $\begin{array}{c}\text { Group } \\
\text { A } \\
\text { Group } \\
\text { B } \\
\end{array}$ & $\begin{array}{c}18.25 \pm 3.86 \\
16.02 \pm \\
3.41 \\
\end{array}$ & $\begin{array}{l}\tilde{b} \\
\dot{0} \\
\mathrm{v}\end{array}$ & $\begin{array}{c}20.41 \pm \\
4.90 \\
17.19 \pm \\
3.29 \\
\end{array}$ & 苞 & $\begin{array}{c}21.7 \pm \\
4.8 \\
18.3 \pm \\
3.62 \\
\end{array}$ & $\stackrel{-}{0}$ & $\begin{array}{c}23.08 \pm \\
4.8 \\
18.51 \pm \\
3.62 \\
\end{array}$ & 官 \\
\hline
\end{tabular}

The time required for giving the block was more in Group B (198.57 \pm 19.56 seconds) compared to Group A (151.53 \pm 14.37 seconds) which was clinically significant ( $p<0.01)$. The encircle time in Group B (16 $\pm 3.32 \mathrm{~min})$ was lesser than

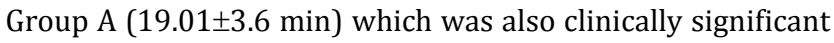
$(\mathrm{p}<0.01)$. The time of onset and completion of sensory and motor block for musculocutaneous, radial, ulnar and median nerve was faster in Group B compared to Group A and all were clinically significant. (Table 3 ) The completeness of block was achieved in 23.41 \pm 4.92 minutes in Group A and
19.01 \pm 3.66 in Group B, showing faster achievement of completeness of block in Group B, which was clinically significant ( $\mathrm{p}$ value $<0.01$ ).

The duration of the block in Group A was $367 \pm 50.49$ minutes, whereas in Group B $388 \pm 49.98$ minutes which was clinically significant ( $\mathrm{p}$ value 0.014 ). 3 patients in Group A $(4.3 \%)$ and 2 patients in Group B (2.9\%) required supplemental intravenous analgesia. No patient required general anaesthesia. There were no side effects noted in both groups.
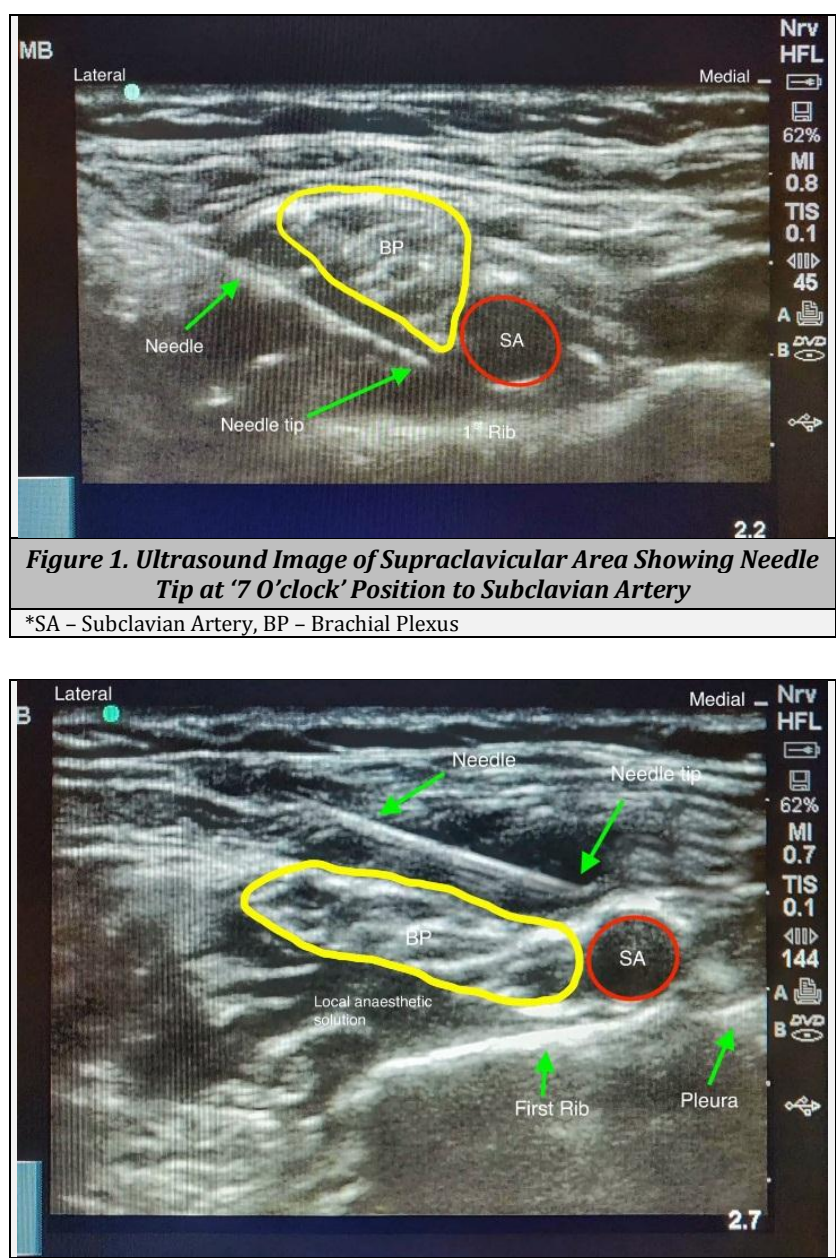

Figure 2. Ultrasound Image of Supraclavicular Area Showing Double Point Technique. Needle Tip at '11 O'clock' Position to Subclavian Artery. Local Anaesthetic Solution Already Deposited Below the Brachial Plexus at 70 'clock Position

*SA - Subclavian Artery, BP - Brachial Plexus

\section{DISCUSSION}

We initiated the study by hypothesizing that ultrasound guided supraclavicular brachial plexus block with the single point technique is equally effective compared to the double point technique. From the literature it is evident that multiple pricks for giving brachial plexus block have led to higher incidence of nerve injury. ${ }^{3,8,9,10}$ This complication can be avoided using ultrasound aid as well as by reducing the number of pricks.12,13 That is where the single point technique as described in our study is beneficial. It reduces the number of pricks and thereby reducing accidental prick to the nerve plexus as well as to other tissues. This is the first study conducted in the Indian subpopulation. This is also the 
only study were Ropivacaine and Lignocaine combination was used, wherein other studies they had used either Lignocaine alone or in combination with Bupivacaine or mepivacaine. ${ }^{3}$

Our study showed that good surgical anaesthesia was attained with both the techniques. This was comparable with other studies where ultrasound guided brachial plexus block with the single injection was equally effective compared to multiple injection techniques.3,9,10,11 The time required for giving block in the single point technique was less compared to the double point technique because it is technically easy, but the onset and completeness of anaesthesia were delayed when compared with the double point technique. In the double point technique, the drug encircled the brachial plexus faster, which might have led to the faster onset and completeness of the anaesthesia. So practically the advantage of less procedural time in the single point technique is negated by its slowness of onset and completion of the block. Thus double point technique can be applicable to patients where we are intending to have a faster onset of block even though double point technique consumed more time during the conduct of the block. The total duration of the block was also more in double point technique compared to single point technique, which has led to more duration of postoperative analgesia.

\section{CONCLUSIONS}

In ultrasound guided brachial plexus block, even though both techniques have satisfactory results, double point technique is superior to the single point technique in terms of onset, completeness and duration of the block, but in terms of simplicity in technicality the single point technique has the upper hand.

\section{REFERENCES}

[1] Rebecca L Johnson, Sandra L Kopp, Jens Kessler, Andrew $\mathrm{T}$ Gray. Peripheral Nerve Blocks and Ultrasound Guidance for Regional Anesthesia. In: 2. Gropper M, Eriksson L, Fleisher L, Wiener-Kronish J, Cohen N, Leslie $\mathrm{K}$, editors. Miller's anesthesia. 9th ed. Philadelphia: Elsevier; 2019. p. 1450-1479.

[2] Ultrasound-Guided Supraclavicular Brachial Plexus Block - NYSORA [Internet]. NYSORA. 2020 [cited 13 January 2020]. Available from: https://www.nysora.com/regional-anesthesia-forspecific-surgical-procedures/upper-extremity-regionalanesthesia-for-specific-surgical-procedures/anesthesiaand-analgesia-for-elbow-and-forearmprocedures/ultrasound-guided-supraclavicular-brachialplexus-block/

[3] Albrecht E, Mermoud J, Fournier N, Kern C, Kirkham K. A systematic review of ultrasound-guided methods for brachial plexus blockade. Anaesthesia. 2015;71(2):213227.

[4] Hyun Jung Kim, Sang Hyun Park, Hye Young Shin, Yun Suk Choi. Brachial Plexus Injury as a Complication after Nerve Block or Vessel Puncture Korean J Pain. 2014 Jul; 27(3): 210-218.

[5] Urban MK, Urquhart B. Evaluation of brachial plexus anesthesia for upper extremity surgery. Reg Anesth. 1994;19:175-182.

[6] Fanelli G, Casati A, Garancini P, Torri G. Nerve stimulator and multiple injection technique for upper and lower limb blockade: failure rate, patient acceptance, and neurologic complications. Study Group on Regional Anesthesia. Anesth Analg. 1999;88:847-852.

[7] Liu S, Ngeow J, John R. Evidence Basis for UltrasoundGuided Block Characteristics. Regional Anesthesia and Pain Medicine. 2010;35(1):26-35.

[8] Roy M, Nadeau M, Côté D, Levesque S, Dion N, Nicole P. Comparison of a Single- or Double-Injection Technique for Ultrasound-Guided Supraclavicular Block. Regional Anesthesia and Pain Medicine. 2012;37(1):55-59.

[9] Techasuk W, González A, Bernucci F, Cupido T, Finlayson R, Tran D. A Randomized Comparison Between DoubleInjection and Targeted Intracluster-Injection Ultrasound-Guided Supraclavicular Brachial Plexus Block. Anesthesia \& Analgesia. 2014;118(6):1363-1369.

[10] Tran D, Muñoz L, Zaouter C, Russo G, Finlayson R. A Prospective, Randomized Comparison Between Singleand Double-Injection, Ultrasound-Guided Supraclavicular Brachial Plexus Block. Regional Anesthesia and Pain Medicine. 2009;34(5):420-424.

[11] Arab S, Alharbi M, Nada E, Alrefai D, Mowafi H. Ultrasound-Guided Supraclavicular Brachial Plexus Block. Anesthesia \& Analgesia. 2014;118(5):1120-1125.

[12] Orebaugh SL, Williams BA, Vallejo M, Kentor ML. Adverse outcomes associated with stimulator-based peripheral nerve blocks with versus without ultrasound visualization. Reg Anesth Pain Med. 2009;34:251-255.

[13] Selander D, Edshage S, Wolff T. Paresthesiae or no paresthesiae? Nerve lesions after axillary blocks. Acta Anaesthesiol

Scand. 1979;23:27-33. 